\title{
STORMWATER QUALITY CONTROL FOR SUSTAINABLE URBAN DRAINAGE SYSTEMS
}

\author{
S. TODESCHINI, S. PAPIRI \& C. CIAPONI \\ Department of Civil Engineering and Architecture, University of Pavia, Pavia, Italy.
}

\begin{abstract}
The paper deals with the performance assessment of stormwater facilities in mitigating the negative effects of urban runoff pollutants carried both to the receiving environment and to the urban drainage system. Experimental campaigns and numerical simulations have been carried out on a residential catchment of Pavia, Lombardia, Italy. The rainfall-runoff process and the pollutant dynamics in the catchment and combined sewer network were simulated using a conceptual model based on an instantaneous unit hydrograph of a single linear reservoir system for individual events as well as for a continuous run of events and inter-event periods over one year. Several design configurations and operating conditions of flow regulators (FRs) and stormwater detention tanks (SWDTs) have been evaluated by defining performance indicators that simultaneously account for a large number of technical, environmental, and socio-economic constraints.

On many occasions, wet-weather pollutant concentrations substantially exceeded what might normally be expected of raw wastewater, which thus required stormwater treatment facilities for the environmental and ecological protection of the receiving water. FR was unable to control the acute pollution impact on the river, thereby causing severe ecological deterioration. SWDT was very appropriate to safeguard both the quantity and the quality of the entire chain, consisting of the sewer system, the treatment plant, and the receiving water. The results of this research provide information about a key issue related to the implementation of environmental policies in large urban areas for the recovery of impacted receiving water bodies.

Keywords: Environment, management, pollution, stormwater, urban catchment.
\end{abstract}

\section{INTRODUCTION}

Many urban areas are drained by combined sewer networks. During a storm, runoff typically collects significant amounts of anthropogenic pollutants as well as naturally occurring materials such as sediments from soil erosion [1-5]. Subsequently, stormwater is mixed with large amounts of urban wastewater in the sewer. When the system becomes saturated by runoff water, the polluted mixture is discharged through combined sewer overflow into the natural environment, severely polluting the downstream ecosystem [6-9].

In recent years, many government and community organizations have placed increasing emphasis on developing and implementing strategies to reduce urban stormwater pollution [10-13]. In many situations, a stormwater detention tank (SWDT) is combined with a flow regulator (FR) to restore impacted water courses [14-17]. In addition, recent directions of Italian and Lombardia Region (Lombardia Regional Law 12 December 2003, N. 26 and Regional Regulations 24 March 2006, N. 3 and 4) legislation on urban stormwater management require FR and SWDT for various situations in urban catchments to safeguard the quality of the receiving water [18].

The aim of this research is the study of the the hydraulic and the environmental behavior of these structural facilities at the final reach of an experimental catchment located in Pavia, northern Italy. A previous study [19] examined some design and operating conditions of FR and SWDT at the outlet of this urban catchment, which is drained by a combined sewer network. This research investigates further configurations of FR and SWDT by varying the insertion in the sewer system, the maximum flow rate directed for treatment by the FR (i.e. L/s per hectare of 
impervious area, $\mathrm{ha}_{\mathrm{imp}}$ ) the size of the tank (i.e. $\mathrm{m}^{3}$ per ha $\mathrm{imp}_{\mathrm{im}}$ ), and the filling and emptying rules of SWDT. The examined design criteria and operating rules of FR and SWDT are implemented using a computer code. Differences between the various solutions are simulated by changing either the algorithm or the model parameters to match the characteristics of the facility. Several performance indicators (PIs) provide a clear description of the behavior of the stormwater facilities, summarizing the diversity and the large amount of information necessary to characterize an urban drainage system and its interactions with both the receiving water course and the treatment plant [20-22].

This research is of particular interest for many reasons. First of all, stormwater runoff in the catchment is characterized by a high contamination level, based on several monitoring campaigns carried out between 2000 and 2003 [23, 24]. Another reason is that the design and operation of stormwater facilities is very complex, with the need to simultaneously account for a great number of technical, environmental and socio-economic constraints. Furthermore, urban waters managers need to be able to predict and assess the performance of stormwater control measures, both individually and in combinations. There is thus a strong demand of predictive models for the performance assessment of stormwater facilities.

\section{MATERIALS AND METHODS}

\subsection{The experimental catchment}

The research focuses on the urban catchment Cascina Scala, Pavia, northern Italy (Fig. 1).

The Cascina Scala catchment is composed exclusively of residential use, supporting approximately 1500 inhabitants. The total contribution area is 12.7 ha, where $62 \%$ of the total area is impervious. The catchment is drained by a combined sewer system with a total length $2045 \mathrm{~m}$ and an average slope of 0.042 ; pipes are made of concrete. The characteristics of the catchment and drainage system are well described in Papiri et al. [24].

The Cascina Scala catchment has been instrumented since 1989, but the rainfall-runoff data were collected systematically from June 2000 to October 2003. During this period, the catchment had two rainfall gauges, a flow gauge at the outlet, a refrigerated automatic grab sampler with 24 bottles, and a multi-parameter water quality probe. The instrumental equipment and the monitoring activity are well described in Barco et al. [23]. A total of 23 rainfall-runoff events were monitored also for the quality aspects and 281 wet-weather samples were analyzed in a certified laboratory (Analytica SRL, Pavia, Italy) following the analytical methods of Italian Water Research Institute of National Research Council [25]. Barco et al. [23] also present basic statistics of monitoring storm events.

\subsection{Rainfall-runoff process and pollutant dynamics on the catchment}

A conceptual model based on the theory of the instantaneous unit hydrograph of a single linear reservoir system has been used to simulate the rainfall-runoff process and the pollutant dynamics on the catchment and sewer network. Quality simulations refer to total suspended solids (TSSs) as an indicator of overall stormwater quality parameters [26]. Code parameters which influence the modeling processes (e.g. the accumulation of pollutants during dry-weather on catchment surfaces; the removal of accumulated pollutants by runoff; the transport of pollutants due to drainage flows) have been tuned through experimental data measured at the Cascina Scala catchment (Table 1). 


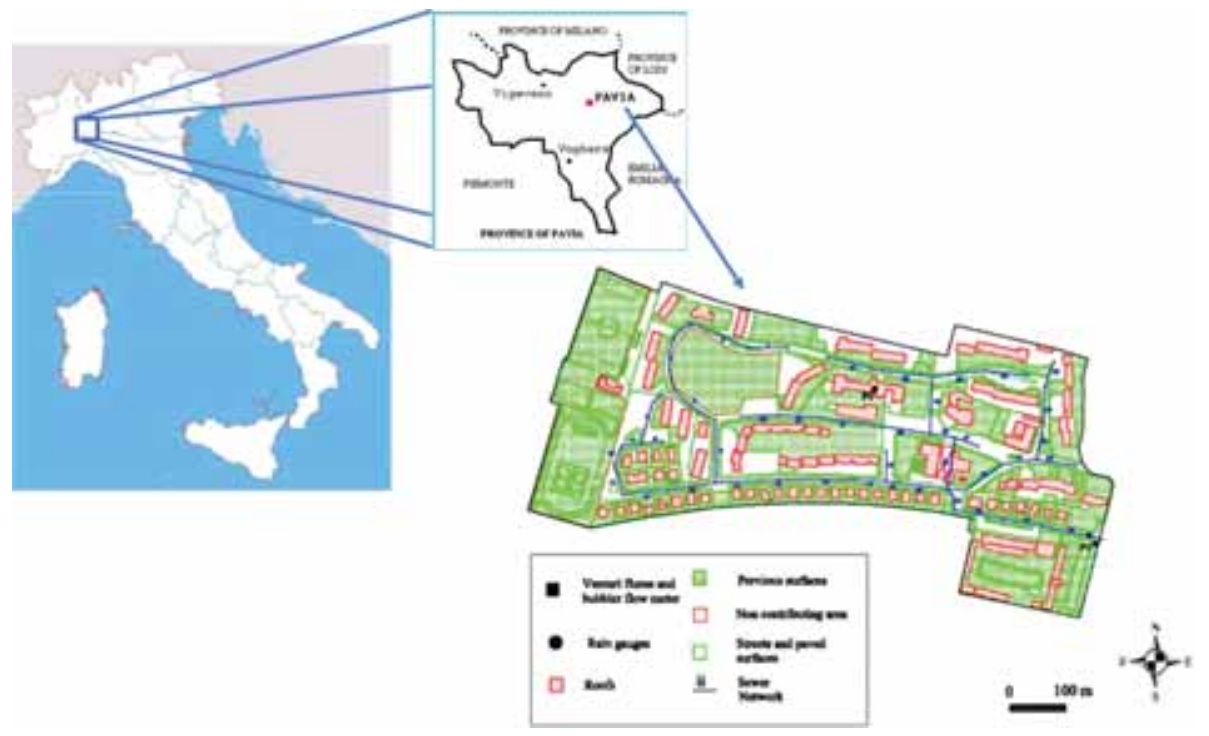

Figure 1: Cascina Scala experimental catchment.

Table 1: Values of the calibration parameters.

\begin{tabular}{|c|c|c|}
\hline Parameter & Value & Unit of measure \\
\hline \multicolumn{3}{|l|}{ Rainfall-runoff process $[9,27]$} \\
\hline \multicolumn{3}{|l|}{ Initial depression storage } \\
\hline Istore & 2 & {$[\mathrm{~mm}]$} \\
\hline Portion of contributing impervious area $\varphi_{\text {imp }}$ & 0.75 & \\
\hline Retention constant $k$ & 8 & {$[\mathrm{~min}]$} \\
\hline \multicolumn{3}{|l|}{ Pollutant dynamics } \\
\hline \multicolumn{3}{|l|}{ Accumulation on the catchment [28] } \\
\hline$B$ & 18 & {$\left[\mathrm{~kg} \mathrm{ha}^{-1} \mathrm{day}^{-1}\right]$} \\
\hline$D$ & 0.3 & {$\left[\right.$ day $\left.^{-1}\right]$} \\
\hline \multicolumn{3}{|l|}{ Wash off of urban surfaces $[29,30]$} \\
\hline rcoef & 0.1 & {$\left[\min ^{-1}\right]$} \\
\hline washpo & 1.2 & {$[-]$} \\
\hline
\end{tabular}

The numerical simulation is carried out for one year from 1/08/2006 to 31/07/2007. Rainfall data belongs to two tipping bucket rain gauges with $0.2 \mathrm{~mm}$ accuracy. According to U.S. Environmental Protection Agency [14] rainfall events are selected on the basis of an interevent time of $6 \mathrm{~h}$. In such a way the independence between contiguous rainfall events is guaranteed at the level of each catchment-sewer network. Storm events with a precipitation depth less than $2 \mathrm{~mm}$ are set apart. Hyetographs are reconstructed with a discretization of $1 \mathrm{~min}$. The total precipitation depth in the examined period is $795.0 \mathrm{~mm}$, while that of the 51 events selected on the basis of the previous 
criteria is $716.3 \mathrm{~mm}$. The total duration of the selected storms is equal to $502 \mathrm{~h}$. Simulated storms cover a wide range of precipitation characteristics: precipitation depth of each event varies in the range of 2.1-103.6 mm; maximum rainfall depth over 1 min ranges between 0.01 and $1.99 \mathrm{~mm}$; the rainfall duration between 18 and $2050 \mathrm{~min}$; the antecedent dry period between 0.25 and 25.94 day. The investigated year exhibits an annual precipitation depth that is very close to the mean value of the annual precipitation depth of Pavia from 1988 to 2007 [24]. All the alluvial plain (Pianura Padana) over northern Italy is characterised by the same precipitation pattern as Pavia.

\subsection{Stormwater FRs and detention tanks}

The operation of FR and SWDT is modeled at the outlet of the sewer network. The design configurations under investigation are shown in Fig. 2: (a) a FR with different flow rate directed for treatment $\left(Q_{\mathrm{FR}}\right)$; (b) an off-line SWDT with an upstream by-pass device (BP) that rules out the tank once full. Different $Q_{\mathrm{FR}}$ and volume of the tank $\left(V_{\mathrm{SWDT}}\right)$ are investigated.

As concerns the operating conditions of the tank, the research investigates a capture tank with an intermittent emptying at the end of stormwater runoff. (A widely circulated classification distinguishes between capture and transit SWDT: in the first type only the first part of the hydrograph is entrapped in the tank and a BP stops the filling once the tank is full. In a transit SWDT the first and the second part of the hydrograph mix together in the tank before stormwater is overflowed into the receiving water body.) During a rainfall event the first part of the runoff is entrapped in the SWDT.

(a)

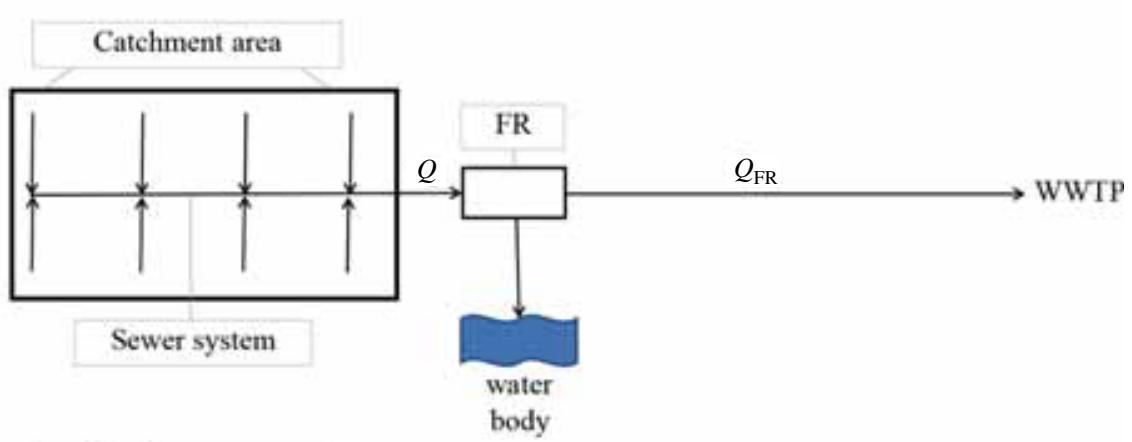

(b)

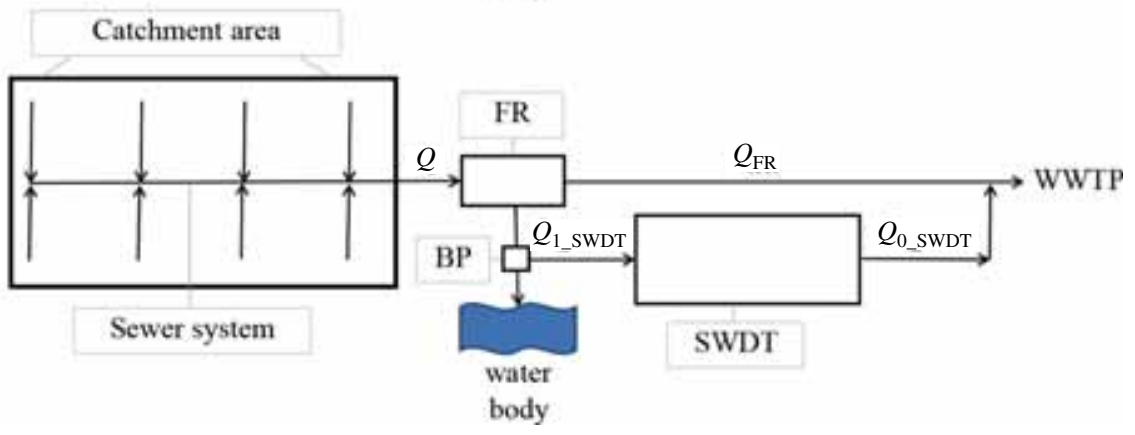

Figure 2: Design configurations. BP: by-pass device; FR: flow regulator; SWDT: stormwater detention tank; WWTP: wastewater treatment plant; Q: stormwater flow rate; $Q_{\mathrm{FR}}$ : flow rate of FR; $Q_{\text {I_SWDT }}$ : filling flow rate of SWDT; $Q_{0 \_S W D T}:$ emptying flow rate of SWDT. 
When the tank is full, a BP rules out the tank and the incoming flow rate exceeding $Q_{\mathrm{FR}}$ is discharged into the river. The emptying of the SWDT begins when the flow rate, which is not directed to the treatment by the FR, becomes less than $0.1 \mathrm{~L} / \mathrm{s}$ and stops when this flow rate exceeds $0.2 \mathrm{~L} / \mathrm{s}$ (the use of two different flow rates provides stability to the system avoiding too close start and stop of the motor pumps used to empty the SWDT). Different emptying flow rate of the tank $\left(Q_{0 \text { SWDT }}\right)$ have been examined. The research examines capture SWDT instead of transit SWDT because the highest pollutant levels of stormwater runoff are included in the first part of the hydrograph (i.e. first flush phenomenon which is well characterized for this catchment by Barco et al. [23]). In this research is considered an intermittent emptying of SWDT instead of continuous emptying because this choice is favored by operators of the treatment plant (wastewater treatment plant or WWTP). The minimum value adopted for $Q_{\mathrm{FR}}$ is $1 \mathrm{~L} / \mathrm{s}$ per ha ${ }_{\text {imp }}$ because at the Cascina Scala catchment, mean dry weather flow rate and peak daily flow rate are slightly lower than $0.5 \mathrm{~L} / \mathrm{s} \mathrm{per} \mathrm{ha}$ imp $_{\text {and }} 1 \mathrm{~L} / \mathrm{s} \mathrm{per} \mathrm{ha}$ imp$_{\text {, }}$, respectively. Simulations are also extended to higher values of $Q_{\mathrm{FR}}$ (i.e. 5 and $10 \mathrm{~L} / \mathrm{s}$ per ha $\mathrm{imp}_{\mathrm{imp}}$ ): even if they are not compatible with the flow capacity of common treatment plant, they could be adopted for an intermediate control of stormwater runoff. $V_{\text {SWDT }}$ is investigated in the range $12.5-75 \mathrm{~m}^{3}$ per ha ${ }_{\text {imp }}$ according to the findings of previous studies on this subject $[16,17]$ and to the prescriptions of Italian and Lombardia Region legislation. The emptying flow rate of the tank varies in the range $0.5-2 \mathrm{~L} / \mathrm{s}$ per $\mathrm{ha}_{\text {imp }}$ because these values fulfill the flow capacity of both the downstream sewer network and the WWTP avoiding a breakdown of the plant capacity (e.g. loss of clarifier sludge blanket). Table 2 shows the list of the simulations carried out and the corresponding parameters' values.

\section{RESULTS AND DISCUSSION}

Numerical modeling of the urban drainage system as described in Sections 2.2 and 2.3 provided useful information for the performance assessment of FR and SWDT. Focal simulation outcomes were included into simple PIs. These synthetic data summarize the diversity and the large amount of information necessary to characterize the system. The complexity is notably due to the rise of users' requirements and to the need of simultaneously account for a great number of technical, environmental and socio-economic constraints.

As concerns one single event the following PIs are examined:

- maximum concentration of pollutant in overflow $\left(C_{\max }\right.$ in $\left.\mathrm{mg} / \mathrm{L}\right)$;

- duration of overflow ( $d$ in min);

- wet-weather TSS mass sent to treatment/wet-weather TSS mass $(\varepsilon)$;

- wet-weather volume sent to treatment/wet-weather volume $(\eta)$;

- SWDT emptying duration $\left(t_{T}\right.$ in $\left.\mathrm{h}\right)$.

On annual basis the following PIs are investigated:

- annual number of overflow (n);

- annual duration of overflow/annual duration of stormwater runoff $\left(\delta_{A}\right)$;

- annual wet-weather TSS mass sent to treatment/annual wet-weather TSS mass $\left(\varepsilon_{A}\right)$;

- annual wet-weather volume sent to treatment/annual wet-weather volume $\left(\eta_{A}\right)$;

- annual maximum SWDT emptying duration $\left(t_{\text {Amax }}\right.$ in $\left.\mathrm{h}\right)$.

These indices referred to annual wet-weather duration including both sewage and stormwater. The first three indicators describe the efforts against biological and chemical river deterioration, the PI $\eta_{A}$ informs about the costs and the charges to the purification as rainwater causes many problems to the 
Table 2: List of simulations for the design configurations of Fig. 2. $Q_{\mathrm{FR}}$ : flow rate of FR per ha ${ }_{\text {imp }}\left[\mathrm{L} \mathrm{s}^{-1}\right.$ ha $\left._{\text {imp }}{ }^{-1}\right] ; V_{\text {SWDT }}$ : volume of SWDT per ha ${ }_{\text {imp }}\left[\mathrm{m}^{3} \mathrm{ha}_{\text {imp }}{ }^{-1}\right] ; Q_{0_{-} \text {SWDT }}$ : emptying flow rate of SWDT per ha $\mathrm{imp}_{\text {imp }}\left[\mathrm{L} \mathrm{s}^{-1} \mathrm{ha}_{\mathrm{imp}}^{-1}\right]$.

\begin{tabular}{|c|c|c|c|c|c|c|c|}
\hline $\mathrm{n}$. & $Q_{\mathrm{FR}}$ & $V_{\text {SWDT }}$ & $Q_{0 \_ \text {SWDT }}$ & n. & $Q_{\mathrm{FR}}$ & $V_{\text {SWDT }}$ & $Q_{0 \_ \text {SWDT }}$ \\
\hline (a) 1 & 1.0 & - & - & (b) 36 & 3.0 & 25 & 1.0 \\
\hline (a) 2 & 1.5 & - & - & (b) 37 & 3.0 & 50 & 1.0 \\
\hline (a) 3 & 2.0 & - & - & (b) 38 & 3.0 & 75 & 1.0 \\
\hline (a) 4 & 3.0 & - & - & (b) 39 & 1.0 & 12.5 & 1.5 \\
\hline (a) 5 & 5.0 & - & - & (b) 40 & 1.0 & 25 & 1.5 \\
\hline (a) 6 & 10 & - & - & (b) 41 & 1.0 & 50 & 1.5 \\
\hline (b) 7 & 1.0 & 12.5 & 0.5 & (b) 42 & 1.0 & 75 & 1.5 \\
\hline (b) 8 & 1.0 & 25 & 0.5 & (b) 43 & 1.5 & 12.5 & 1.5 \\
\hline (b) 9 & 1.0 & 50 & 0.5 & (b) 44 & 1.5 & 25 & 1.5 \\
\hline (b) 10 & 1.0 & 75 & 0.5 & (b) 45 & 1.5 & 50 & 1.5 \\
\hline (b) 11 & 1.5 & 12.5 & 0.5 & (b) 46 & 1.5 & 75 & 1.5 \\
\hline (b) 12 & 1.5 & 25 & 0.5 & (b) 47 & 2.0 & 12.5 & 1.5 \\
\hline (b) 13 & 1.5 & 50 & 0.5 & (b) 48 & 2.0 & 25 & 1.5 \\
\hline (b) 14 & 1.5 & 75 & 0.5 & (b) 49 & 2.0 & 50 & 1.5 \\
\hline (b) 15 & 2.0 & 12.5 & 0.5 & (b) 50 & 2.0 & 75 & 1.5 \\
\hline (b) 16 & 2.0 & 25 & 0.5 & (b) 51 & 3.0 & 12.5 & 1.5 \\
\hline (b) 17 & 2.0 & 50 & 0.5 & (b) 52 & 3.0 & 25 & 1.5 \\
\hline (b) 18 & 2.0 & 75 & 0.5 & (b) 53 & 3.0 & 50 & 1.5 \\
\hline (b) 19 & 3.0 & 12.5 & 0.5 & (b) 54 & 3.0 & 75 & 1.5 \\
\hline (b) 20 & 3.0 & 25 & 0.5 & (b) 55 & 1.0 & 12.5 & 2.0 \\
\hline (b) 21 & 3.0 & 50 & 0.5 & (b) 56 & 1.0 & 25 & 2.0 \\
\hline (b) 22 & 3.0 & 75 & 0.5 & (b) 57 & 1.0 & 50 & 2.0 \\
\hline (b) 23 & 1.0 & 12.5 & 1.0 & (b) 58 & 1.0 & 75 & 2.0 \\
\hline (b) 24 & 1.0 & 25 & 1.0 & (b) 59 & 1.5 & 12.5 & 2.0 \\
\hline (b) 25 & 1.0 & 50 & 1.0 & (b) 60 & 1.5 & 25 & 2.0 \\
\hline (b) 26 & 1.0 & 75 & 1.0 & (b) 61 & 1.5 & 50 & 2.0 \\
\hline (b) 27 & 1.5 & 12.5 & 1.0 & (b) 62 & 1.5 & 75 & 2.0 \\
\hline (b) 28 & 1.5 & 25 & 1.0 & (b) 63 & 2.0 & 12.5 & 2.0 \\
\hline (b) 29 & 1.5 & 50 & 1.0 & (b) 64 & 2.0 & 25 & 2.0 \\
\hline (b) 30 & 1.5 & 75 & 1.0 & (b) 65 & 2.0 & 50 & 2.0 \\
\hline (b) 31 & 2.0 & 12.5 & 1.0 & (b) 66 & 2.0 & 75 & 2.0 \\
\hline (b) 32 & 2.0 & 25 & 1.0 & (b) 67 & 3.0 & 12.5 & 2.0 \\
\hline (b) 33 & 2.0 & 50 & 1.0 & (b) 68 & 3.0 & 25 & 2.0 \\
\hline (b) 34 & 2.0 & 75 & 1.0 & (b) 69 & 3.0 & 50 & 2.0 \\
\hline (b) 35 & 3.0 & 12.5 & 1.0 & (b) 70 & 3.0 & 75 & 2.0 \\
\hline
\end{tabular}


normal operation of the treatment plant (e.g. wash-out for the sedimentation tank; bulking-foaming; increase of the sludge volume index). The last indicator $t_{\text {Amax }}$ pays attention to the probability of dangerous anaerobic conditions and putrefaction phenomena [31].

\subsection{Performance of stormwater facilities for the examined storms}

In order to facilitate the performance assessment of FR and SWDT, Fig. 3 shows basic statists of maximum pollutant concentration $\left(C_{\max }\right.$ in $\left.\mathrm{mg} / \mathrm{L}\right)$, mean pollutant concentration $(E M C$ in $\mathrm{mg} / \mathrm{L})$, and wet-weather runoff duration $(d$ in $\mathrm{h}$ ). Maximum and mean concentrations exhibit very critical values; the mean of $C_{\max }$ is about $1200 \mathrm{mg} / \mathrm{L}$, the mean of $E M C$ is greater than $500 \mathrm{mg} / \mathrm{L}$. All the pollutant parameters cover a wide range of values depending on the characteristics of storms.

\subsubsection{FRs}

Simulation outcomes demonstrate that FRs cannot reduce significantly the pollutant concentrations discharged into the river. The mean value of maximum overflow concentrations is very high for all the flow rate of FR under investigation (Fig. 4). The high coefficient of variation proves that the efficacy at reducing the pollutant concentrations changed widely with different storms. Also the duration of overflow depends principally on the precipitation characteristics (Fig. 5). The mean value of this indicator significantly decreases for increasing flow rate directed for treatment.

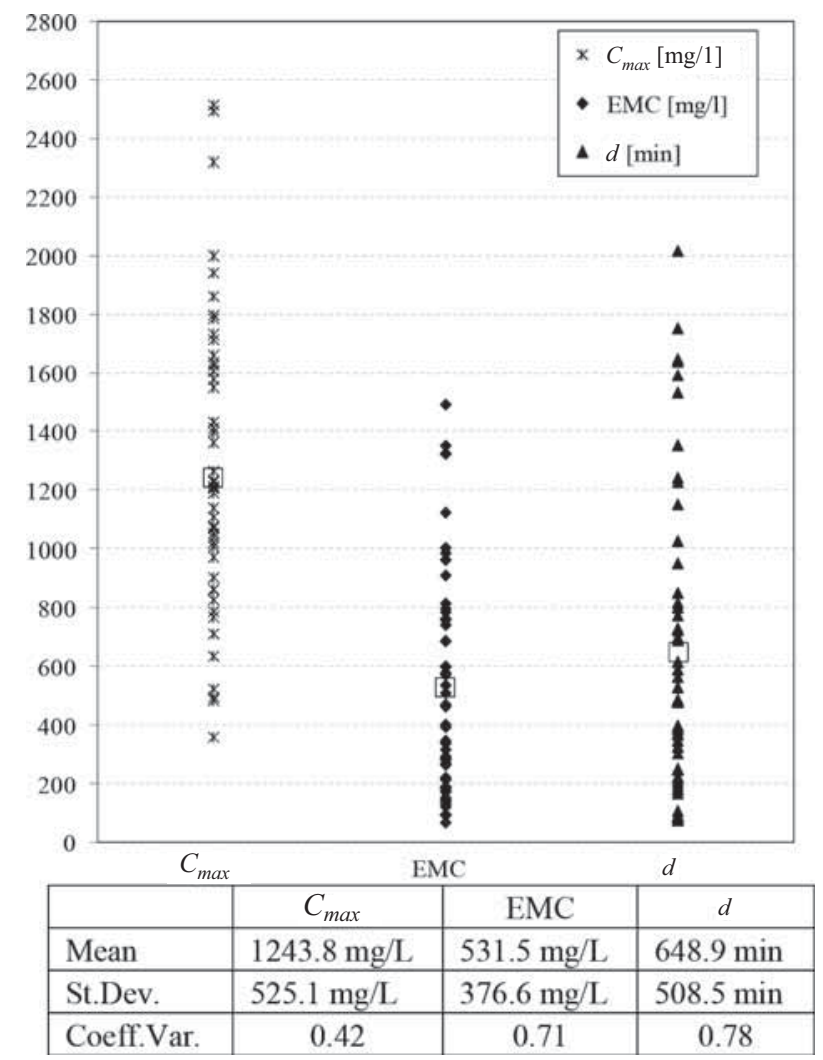

Figure 3: Basic statistics of wet-weather runoff for the examined storms. 


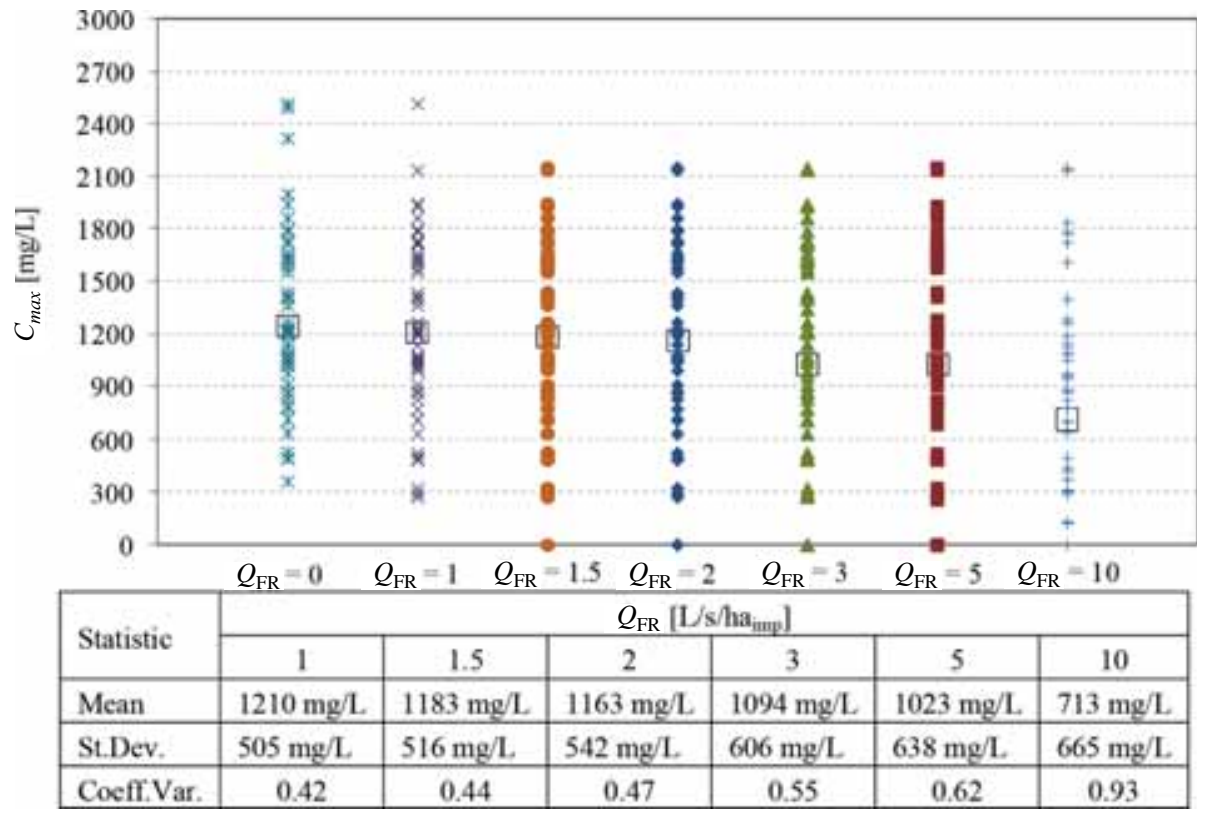

Figure 4: Basic statistics of maximum concentration in the overflow $\left(C_{\max }\right)$ for different flow rate of FR. Simulations of Table 2 from (a) 1 to (a) 6 .

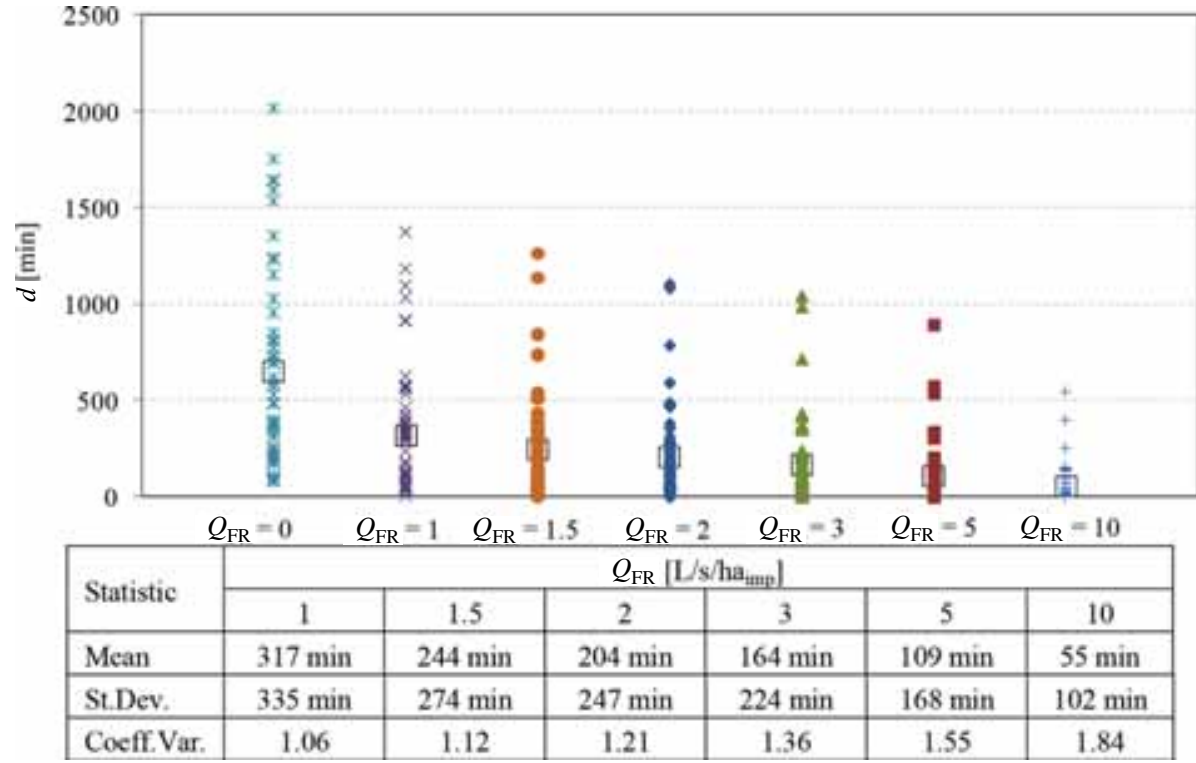

Figure 5: Basic statistics of the duration of overflow $(d)$ for different flow rate of FR. Simulations of Table 2 from (a) 1 to (a) 6. 


\subsubsection{FRs and SWDTs}

The pollutant concentrations in the overflow are considerably reduced by the insertion of SWDT

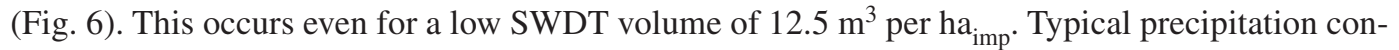
ditions of northern Italy favor a significant first flush phenomenon in wet-weather runoff, thus, increasing the performance of SWDT against environmental pollution. Some values of TSS maximum concentration in overflow increase passing the SWDT volume from 50 to $75 \mathrm{~m}^{3}$ per ha $\mathrm{imp}_{\text {. }}$. The emptying duration is significantly greater for a volume of $75 \mathrm{~m}^{3}$ per ha $\mathrm{imp}_{\mathrm{m}}$ than for a volume of

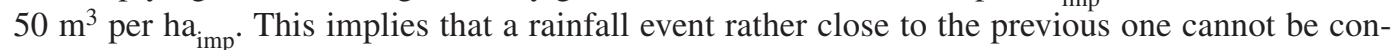
veyed in the SWDT since a new filling of the tank is possible only when the SWDT has completed its emptying cycle. The analysis also highlights a decreasing duration of overflow for increasing volume of the SWDT (Fig. 7): the mean value almost halved passing from 0 to $50 \mathrm{~m}^{3}$ per ha ${ }_{\text {imp }}$. Mean values of both the maximum TSS concentration and duration of overflow do not change substantially passing from 50 to $75 \mathrm{~m}^{3}$ per ha ${ }_{\text {imp. }}$. Figure 8 shows the SWDT emptying durations for the examined storms. The mean value increases for increasing volume of SWDT: it is $6.4 \mathrm{~h}$ for a vol-

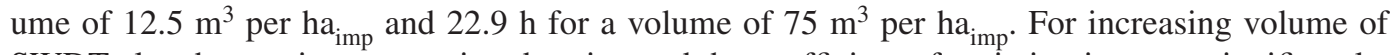
SWDT also the maximum empting duration and the coefficient of variation increase significantly. The maximum emptying duration is over $60 \mathrm{~h}$ for a SWDT volume of $75 \mathrm{~m}^{3}$ per ha $\mathrm{imp}_{\text {imp }}$. This emptying time results in a very high probability of dangerous anaerobic conditions, putrefaction phenomena, and offensive odors, thus, an emptying flow rate greater than $0.5 \mathrm{~L} / \mathrm{s}$ per ha $\mathrm{imp}_{\text {is }}$ required for this SWDT volume.

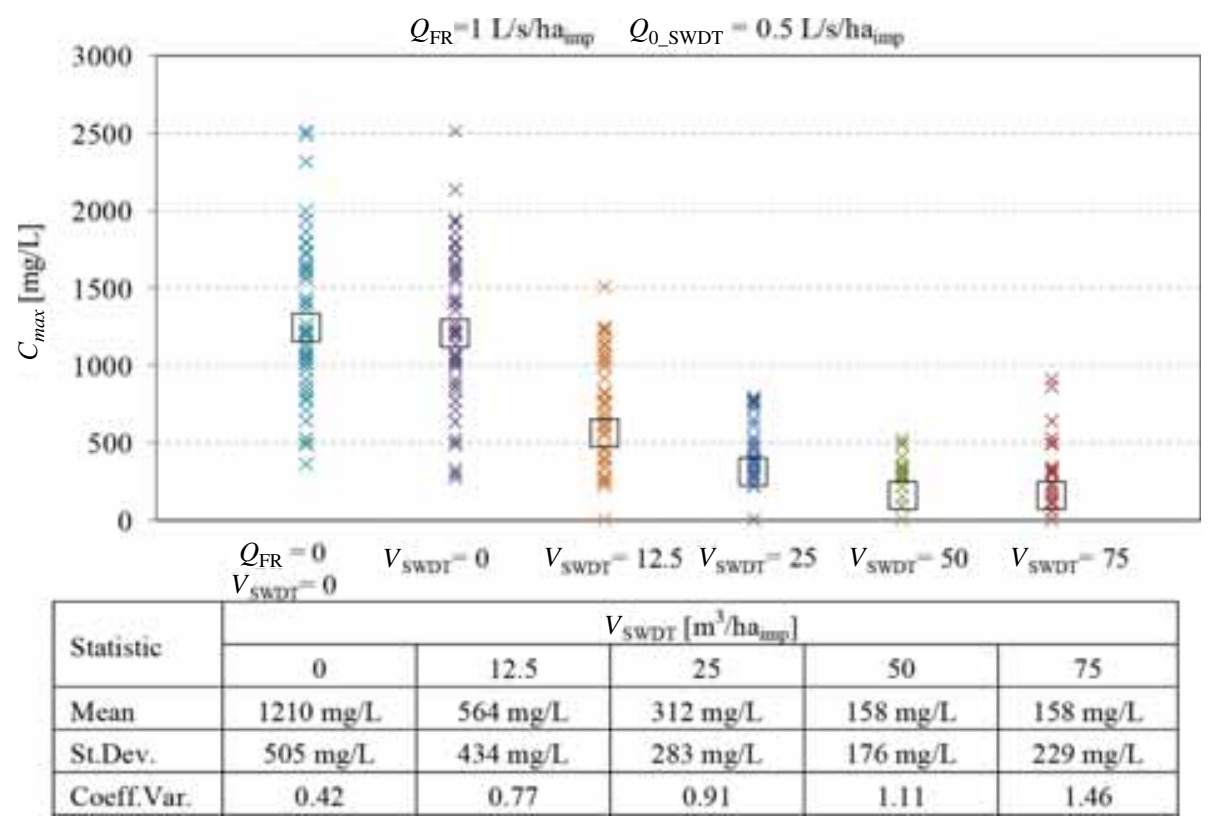

Figure 6: Basic statistics of maximum concentration in the overflow $\left(C_{\max }\right)$ for different volume of SWDT. Simulations of Table 2 from (b) 7 to (b) 10 and a (1). 


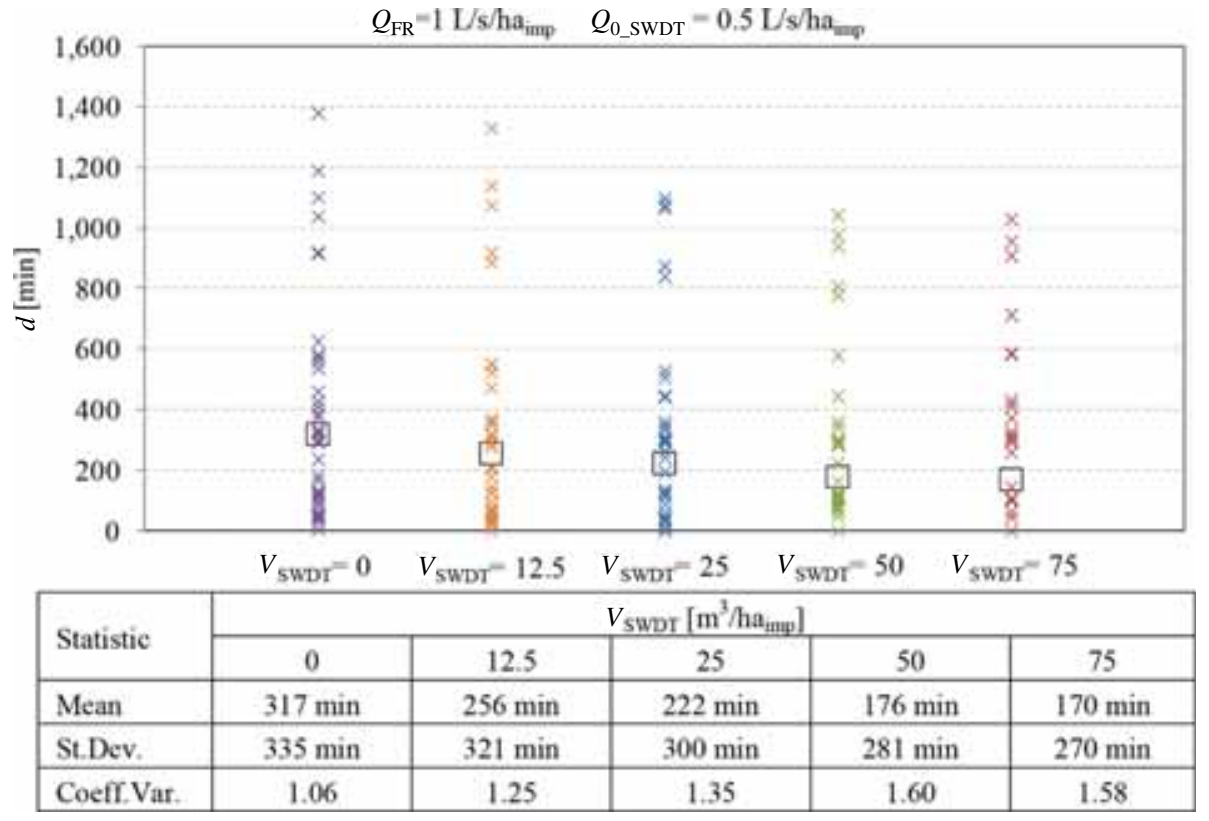

Figure 7: Basic statistics of duration of overflow $(d)$ for different volume of SWDT. Simulations of Table 2 from (b) 7 to (b) 10 and a (1).

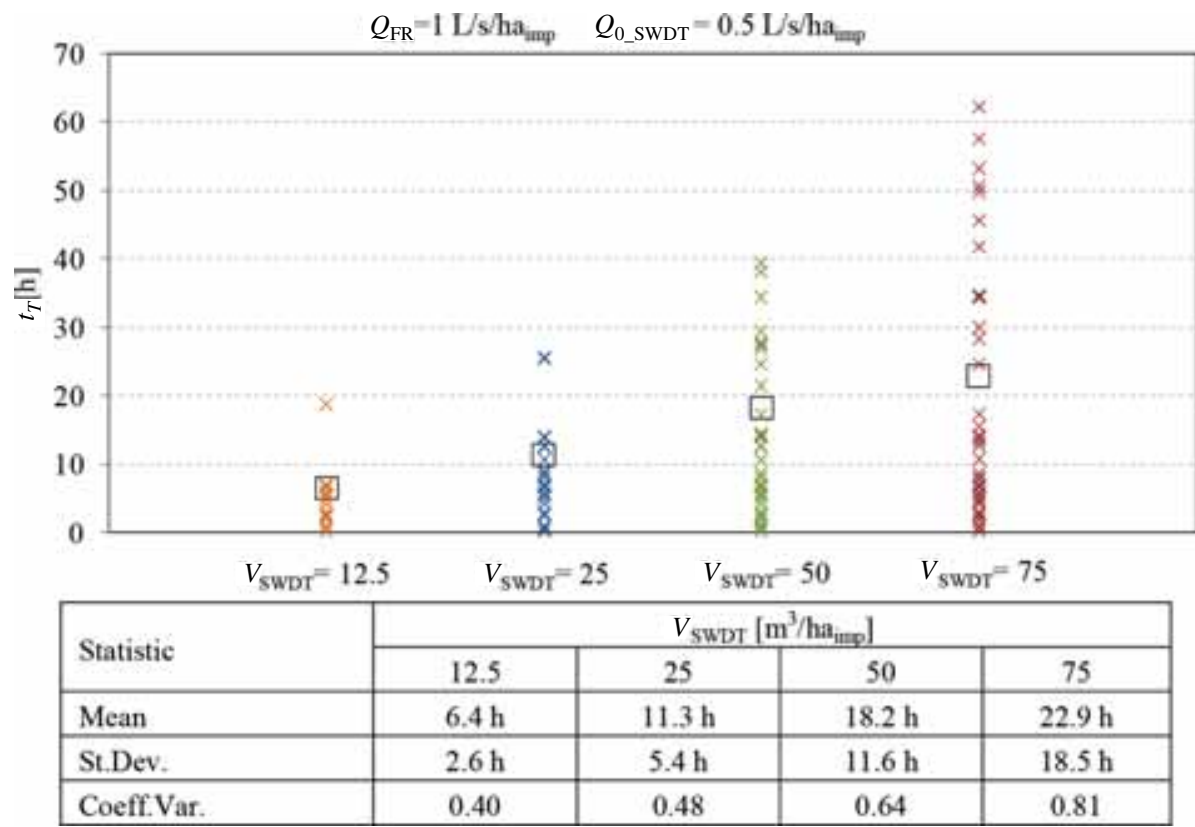

Figure 8: Basic statistics of SWDT emptying duration $\left(t_{T}\right)$ for different volume of SWDT. Simulations of Table 2 from (b) 7 to (b) 10. 


\subsection{Annual performance of stormwater facilities}

Annual number of overflow significantly decreases for increasing volume of the SWDT (Fig. 9). The number of overflow weakly decreases for increasing flow rate of the FR. The number of overflow is a little lower than 20 even if a volume of $75 \mathrm{~m}^{3}$ per ha $\mathrm{imp}_{\text {p }}$ is adopted. Typical precipitation conditions of northern Italy prevent a more significant limitation of the number of sewer discharges into the river.

As concerns the wet-weather pollutant mass and volume of water sent for treatment, simulation outcomes exhibit a positive trend with the volume of the SWDT and flow rate of the FR (Figs 10 and 11). The TSS mass directed to the treatment has a significant uptrend passing from 0 to $25 \mathrm{~m}^{3}$ per ha $\mathrm{imp}_{\text {, }}$, a weaker increasing tendency from 25 to $50 \mathrm{~m}^{3}$ per ha ${ }_{\text {imp }}$, an even lower uptrend for a SWDT volume

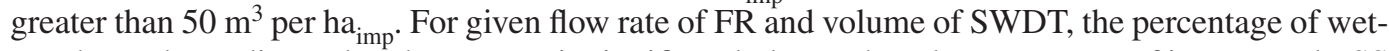
weather volume directed to the WWTP is significantly lower than the percentage of intercepted TSS mass because of the first flush phenomenon in wet-weather runoff. A SWDT volume of $50 \mathrm{~m}^{3}$ per $\mathrm{ha}_{\text {imp }}$ intercepts at least the $90 \%$ of the wet-weather pollutant mass, and at the same time, directs for treatment about the $50 \%$ of annual wet-weather volume.

Figure 12 shows the annual maximum SWDT emptying duration for different volume and emptying flow rate of the tank. According to Fig. 8, maximum emptying duration increases for increasing volume of SWDT. The emptying duration is also considerably influenced by the value of the emptying flow rate. Varying the emptying flow rate of the tank from 0.5 to $2.0 \mathrm{~L} / \mathrm{s} \mathrm{per} \mathrm{ha}$ imp, the annual maximum emptying duration is significantly reduced: it passes from $62.2 \mathrm{~h}$ to $10.5 \mathrm{~h}$ for a SWDT volume of $75 \mathrm{~m}^{3}$ per ha $\mathrm{imp}_{\text {. The }}$. Thend of the emptying durations suggests to adopt an emptying flow rate of the tank of at least $1 \mathrm{~L} / \mathrm{s}$ per ha ${ }_{\text {imp }}$, especially for volume of SWDT greater than $25 \mathrm{~m}^{3}$ per ha ${ }_{\text {imp }}$.

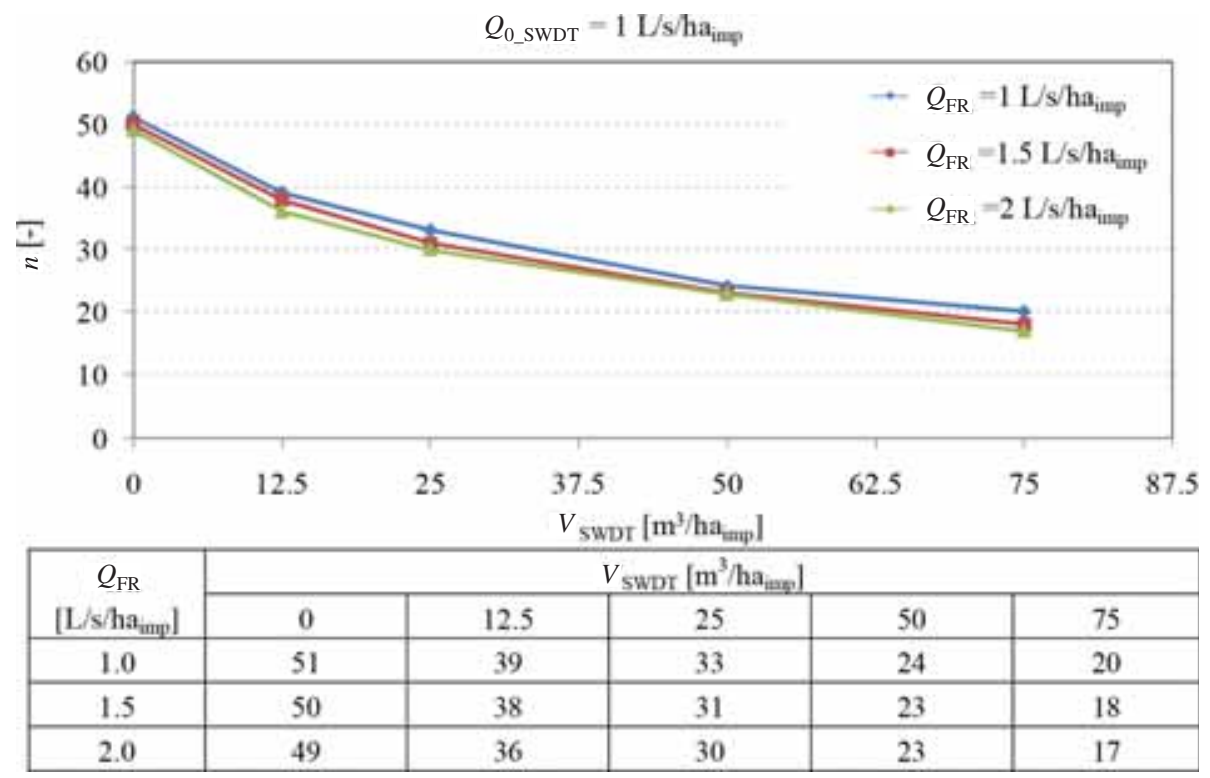

Figure 9: Annual number of overflow ( $n$ ) for different flow rate of FR and volume of SWDT. Simulations of Table 2 from (a) 1 to (a) 3 and from (b) 23 to (b) 34 . 


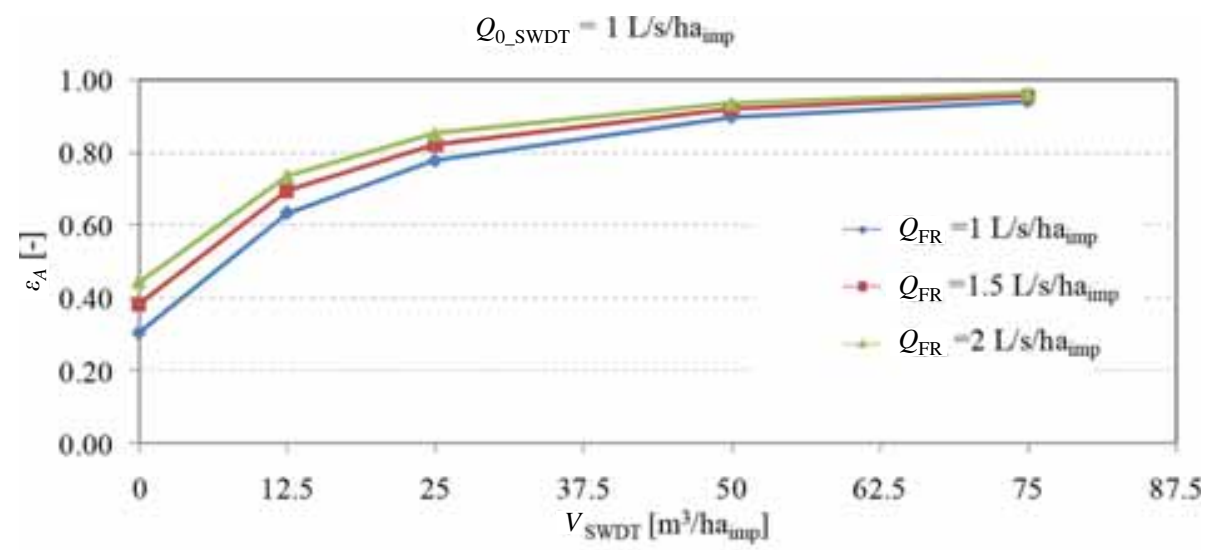

\begin{tabular}{|c|c|c|c|c|c|}
\hline \multirow{2}{*}{$\begin{array}{c}Q_{\mathrm{FR}} \\
{\left[\mathrm{U} / \mathrm{sa}_{\text {mimp }}\right]}\end{array}$} & \multicolumn{5}{|c|}{$V_{\text {SWDT }}\left[\mathrm{m}^{3} / \mathrm{ha}_{\text {imq }}\right]$} \\
\hline 1.0 & 0 & 12.5 & 25 & 50 & 75 \\
\hline 1.5 & 0.31 & 0.63 & 0.78 & 0.90 & 0.94 \\
\hline 2.0 & 0.45 & 0.70 & 0.82 & 0.92 & 0.95 \\
\hline
\end{tabular}

Figure 10: Annual wet-weather TSS mass sent to treatment/annual wet-weather TSS mass $\left(\varepsilon_{A}\right)$ for different flow rate of FR and volume of SWDT. Simulations of Table 2 from (a) 1 to (a) 3 and from (b) 23 to (b) 34 .

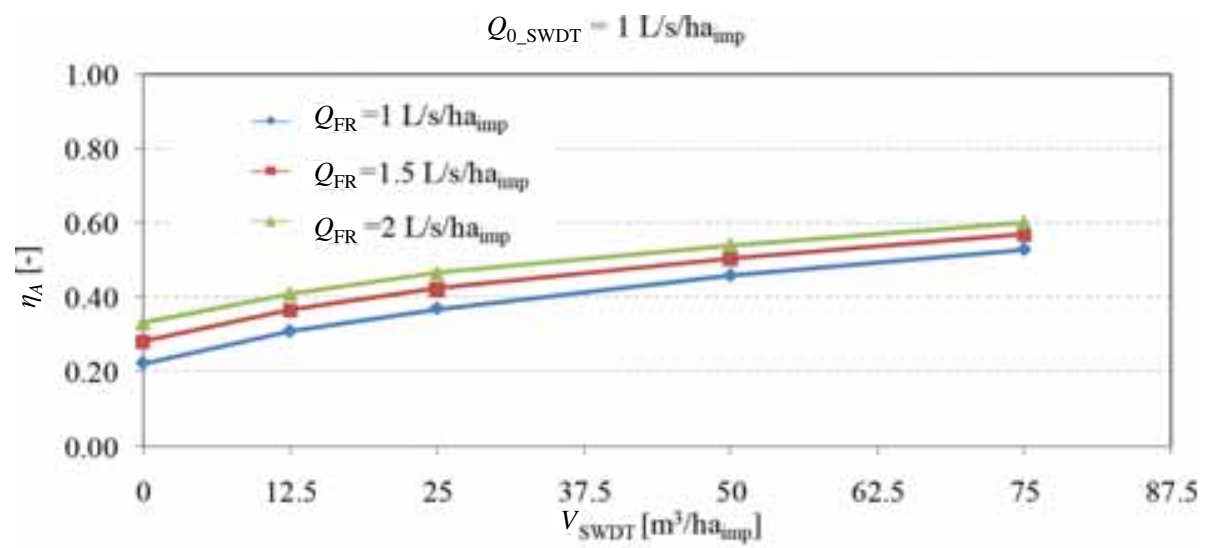

\begin{tabular}{|c|c|c|c|c|c|}
\hline \multirow{2}{*}{$\begin{array}{c}Q_{\mathrm{FR}} \\
{\left[\mathrm{L} / \mathrm{s}_{\mathrm{h}} \mathbf{h} \text { img }\right]}\end{array}$} & \multicolumn{5}{|c|}{$V_{\text {SwDr }}\left[\mathrm{m}^{3} / \mathrm{ha}_{\text {ind }}\right]$} \\
\hline 1.0 & 0 & 12.5 & 25 & 50 & 75 \\
\hline 1.5 & 0.22 & 0.31 & 0.37 & 0.46 & 0.53 \\
\hline 2.0 & 0.33 & 0.36 & 0.42 & 0.50 & 0.57 \\
\hline
\end{tabular}

Figure 11: Annual wet-weather volume sent to treatment/annual wet-weather volume $\left(\eta_{A}\right)$ for different flow rate of FR and volume of SWDT. Simulations of Table 2 from (a) 1 to (a) 3 and from (b) 23 to (b) 34 . 


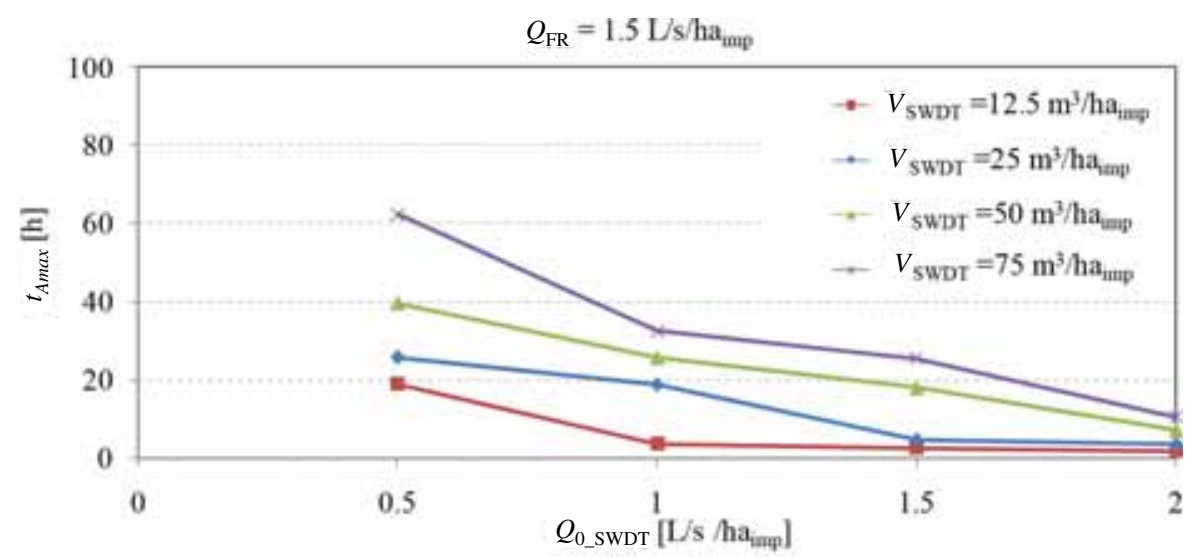

\begin{tabular}{|c|c|c|c|c|}
\hline \multirow{2}{*}{$\begin{array}{c}Q_{0 \_S W D T} \\
{\left[\mathrm{~L} / \mathrm{s} / \mathrm{ha}_{\text {mip }}\right]}\end{array}$} & \multicolumn{4}{|c|}{$V_{\text {SwDT }}\left[\mathrm{m}^{3} / \mathrm{ha}_{\text {ind }}\right]$} \\
\hline 0.5 & 12.5 & 25 & 50 & 75 \\
\hline 1.0 & $18.7 \mathrm{~h}$ & $25.6 \mathrm{~h}$ & $39.4 \mathrm{~h}$ & $62.2 \mathrm{~h}$ \\
\hline 1.5 & $3.5 \mathrm{~h}$ & $18.7 \mathrm{~h}$ & $25.5 \mathrm{~h}$ & $32.4 \mathrm{~h}$ \\
\hline 2.0 & $2.4 \mathrm{~h}$ & $4.7 \mathrm{~h}$ & $17.7 \mathrm{~h}$ & $25.5 \mathrm{~h}$ \\
\hline & $1.8 \mathrm{~h}$ & $3.5 \mathrm{~h}$ & $7.0 \mathrm{~h}$ & $10.5 \mathrm{~h}$ \\
\hline
\end{tabular}

Figure 12: Annual maximum SWDT emptying duration $\left(t_{\text {Amax }}\right)$ for different volume of SWDT and emptying flow rate of SWDT. Simulations of Table 2 from (b) 11 to (b) 14, from (b) 27 to (b) 30, from (b) 43 to (b) 46, and from (b) 59 to (b) 62.

\section{CONCLUSIONS}

This research demonstrated that urban stormwater is one of the main contributors to the deterioration of river water quality. Therefore, effective stormwater treatment is a crucial goal for the environmental and ecological protection of receiving water bodies. This experimental and numerical investigation focused on the ability of common stormwater facilities (i.e. FR and SWDT) in a residential district of Pavia to recover an impacted water course. The analysis showed that collecting the maximum amount of the early part of the runoff in a SWDT proved to be a better strategy than establishing a constant wet-weather flow rate. Typical precipitation conditions of northern Italy often result in a first flush phenomenon in wet-weather runoff; thus, collecting the first flush improves the performance of SWDTs as opposed to installing only FRs for pollution mitigation in the river. As concerns northern Italy, this result can be generalized for catchment area in the range of 5-50 ha and slope of the drainage network in the range of $0.2-1 \%$ as in Todeschini et al. [17]. A rainstorm pattern other than the one under investigation could result in a different performance of the examined stormwater facilities. Anyway, the methodological approach is still applicable. The performance analysis of the investigated stormwater control devices was developed by adopting an integrated approach, thus providing useful information for the selection of design criteria, operating rules, and maintenance strategies of stormwater facilities to safeguard the quantity and quality of the entire sewer systemtreatment plant-receiving natural environment chain. Satisfactory PIs have been obtained with fairly low flow rate of FR (i.e. $1-2 \mathrm{~L} / \mathrm{s}$ per ha $\mathrm{imp}_{\text {}}$ ) and tank volume of about $25-50 \mathrm{~m}^{3} \mathrm{per} \mathrm{ha}_{\text {imp. Intermittent }}$ emptying of the tank at the end of stormwater runoff limited the volumes of water sent for treatment. An emptying flow rate of $1-1.5 \mathrm{~L} / \mathrm{s}$ per ha $a_{\text {imp }}$ has prevented dangerous putrefaction phenomena and offensive odors in the tank and also avoided a breakdown of the treatment plant capacity. These 
results represent a key consideration for the implementation of stormwater control devices that are required in many situations to address environmental problems caused by urbanization, including biodiversity loss and the deterioration of aquatic ecosystems.

\section{ACKNOWLEDGMENTS}

The authors thank the anonymous reviewers for their highly appreciated criticisms and suggestions.

\section{REFERENCES}

[1] Ellis, J.B., Pollutional aspects of urban runoff. Urban Runoff Pollution, eds. H.C. Torno, J. Marsalek \& M. Desbordes, NATO ASI Series G: Vol. 10 Springer-Verlag, pp. 1-38, 1985.

[2] Pitt R., Maestre A., Morquecho R. \& Williamson D., Collection and examination of a municipal separate storm sewer database. Stormwater and Urban Water Systems Modelling, Models and Applications to Urban Water Systems, Vol. 12, ed. W. James, CHI, Guelph, Ontario, pp. 257-294, 2004.

[3] Eriksson, E., Baun, A., Scholes, L., Ledin, A., Ahlman, S., Revitt, M., Noutsopoulos, C. \& Mikkelsen, P.S., Selected stormwater priority pollutants - a European perspective. Science of the Total Environment, 383(1-3), pp. 41-51, 2007. doi: http://dx.doi.org/10.1016/j.scitotenv.2007.05.028

[4] Kim, G., Yur, J. \& Kim, J., Diffuse pollution loading from urban stormwater runoff in Daejeon, Korea. Journal of Environmental Management, 85(1), pp. 9-16, 2007. doi: http://dx.doi. org/10.1016/j.jenvman.2006.07.009

[5] Ballo, S., Liu, M., Hou, L. \& Chang, J., Pollutants in stormwater runoff in Shanghai (China): Implications for management of urban runoff pollution. Progress in Natural Science, 19(7), pp. 873-880, 2009. doi: http://dx.doi.org/10.1016/j.pnsc.2008.07.021

[6] Borchardt, D. \& Sperling, F., Urban stormwater discharges: Ecological effects on receiving waters and consequences for technical measures. Water Science and Technology, 36(8-9), pp. 173-178, 1997.

[7] Even, S., Poulin, M., Mouchel, J.M., Seidl, M. \& Servais, P., Modelling oxygen deficits in the Seine River downstream of combined sewer overflows. Ecological Modelling, 173(2-3), pp. 177-196, 2004.

[8] Tixier, G., Lafont, M., Grapentine, L., Rochfort, Q. \& Marsalek, J., Ecological risk assessment of urban stormwater ponds: Literature review and proposal of a new conceptual approach providing ecological quality goals and the associated bioassessment tools. Ecological Indicators, 11(6), pp. 1497-1506, 2011.

[9] Todeschini, S., Papiri, S. \& Sconfietti, R., Impact assessment of urban wet-weather sewer discharges on the Vernavola river (Northern Italy). Civil Engineering and Environmental Systems, 28(3) pp. 209-229. doi: http://dx.doi.org/10.1080/10286608.2011.584341

[10] U.S. Environmental Protection Agency, National Pollutant Discharge Elimination Systems Watershed Strategy (No. 833R96002). EPA, US, 1994.

[11] European Water Framework Directive, Directive 2000/60/EC. Official Journal of the European Union 327, 22 December 2000, pp. 1-73, 2000.

[12] Maksimovic, C.T. \& Tejada-Guibert, J.A., Frontiers in Urban Water Management; Deadlock or Hope, IWA Publishing and UNESCO (Eds.): London, UK, 2001.

[13] Copeland, C., Clean Water Act: A Summary of the Law. Report No. RL30030. Congressional Research Service: Washington, DC, 2010.

[14] U.S. Environmental Protection Agency, Methodology for Analysis of Detention Basins for Control of Urban Runoff Quality. USEPA 440/5-87-001, Washington DC, USA, 1986. 
[15] Bertrand-Krajewski, JL. \& Chebbo, G., Sizing ratios for stormwater treatment facilities. Proceedings of the 9th International Conference on Urban Drainage, Portland (USA) September 8-13, 2002.

[16] Calabrò, P.S. \& Viviani, G., Simulation of the operation of detention tanks. Water Research 40(1), pp. 83-90, 2006. doi: http://dx.doi.org/10.1016/j.watres.2005.10.025

[17] Todeschini, S., Papiri, S. \& Ciaponi, C., Performance of stormwater detention tanks for urban drainage systems in northern Italy. Journal of Environmental Management, 101: pp. 33-45, 2012. doi: http://dx.doi.org/10.1016/j.jenvman.2012.02.003

[18] Todeschini, S., Trends in long daily rainfall series of Lombardia (Northern Italy) affecting urban stormwater control. International Journal of Climatology, 32(6) pp. 900-919, 2012. doi: http://dx.doi.org/10.1002/joc.2313

[19] Todeschini, S. \& Papiri, S., Performance of stormwater detention tanks in an experimental catchment of northern Italy. WIT Transactions on the Built Environment, 122 pp. 273-284, 2012. doi: http://dx.doi.org/10.2495/UW120241

[20] Harremoës, P. \& Rauch, W., Optimal design and real time control of the integrated urban run-off system. Hydrobiologia, 410(1), pp. 177-184, 1999. doi: http://dx.doi.org/10.1023/ A:1003877829929

[21] Welker, A., Leinweber, U., Klepiszewski, K. \& Schmitt T.G., Effects of integrated stormwater management strategies on the combined sewer system and the wastewater treatment plantriver system. Water Science and Technology, 39(2), pp. 151-157, 1999. doi: http://dx.doi.org/ 10.1016/S0273-1223(99)00019-0

[22] Wong T.H.F., Fletcher T.D., Duncan H.P. \& Jenkins G.A., Modelling urban stormwater treatment: a unified approach. Ecological Engineering, 27(1), pp. 58-70, 2006. doi: http://dx.doi. org/10.1016/j.ecoleng.2005.10.014

[23] Barco, O.J., Papiri, S. \& Stenstrom, M.K., First flush in a combined sewer system. Chemosphere, 71(5), pp. 827-833, 2008. doi: http://dx.doi.org/10.1016/j.chemosphere.2007.11.049

[24] Papiri, S., Ciaponi, C. \& Todeschini, S., The Experimental Urban Catchment of Cascina Scala (Pavia): Rainfall, Runoff and Quality of Sewer Discharges from 1987 to 2006. Aracne Eds. Rome, Italy: (in Italian), pp. 1-268, 2008.

[25] IRSA-CNR, Analytical Methods for Water, User's Manual. Milano, Italy (in Italian), ISBN: 88-448-0083-7, 2000.

[26] Kayhanian, M., Rasa, E., Vichare, A. \& Leatherbarrow, J.E., Utility of suspended solid measurements for storm-water runoff treatment. Journal of Environmental Engineering, 134(9), pp. 712-721, 2008. doi: http://dx.doi.org/10.1061/(ASCE)0733-9372(2008)134:9(712)

[27] Ciaponi, C., Mutti, M. \& Papiri, S., A conceptual model for the estimation on load-graphs in sewer networks during meteorological events. 2nd Int. Conference New Trends in Water and Environmental Engineering, Capri (Italy), ISBN: 88-900282-2-X, CSDU Milan, Italy, 2002.

[28] Alley, W.M. \& Smith, P.E., Estimation of accumulation parameters for urban runoff quality modelling. Water Resources Research, 17(6), pp. 1957-1664, 1981. doi: http://dx.doi. org/10.1029/WR017i006p01657

[29] Sartor, J.D., Boyd, G.B. \& Agardy, F.J., Water pollution aspects of street surface contaminants. Journal of Water Pollution Control Federation 46(3), pp. 458-667, 1974.

[30] Huber, W.C. \& Dickinson, R.E., Storm Water Management Model: User's Manual. EPA Athens: Georgia, 1988.

[31] Kabir, E., Kim, K.H., Ahn, J.W., Hong, O.F. \& Chang Y.S., Offensive odorants released from stormwater catch basin (SCB) in an urban area. Chemosphere, 81(3), pp. 327-338, 2010. doi: http://dx.doi.org/10.1016/j.chemosphere.2010.07.028 